UNIVERSITAS AHMAD DAHLAN

BAHASTRA

http://journal.uad.ac.id/index.php/BAHASTRA

\title{
Pengenalan budaya melalui novel Entrok karya Okky Madasari bagi Pembelajar BIPA
}

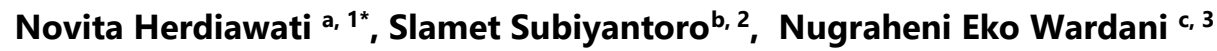 \\ a Pendidikan Bahasa dan Sastra Daerah, Pascasarjana, Universitas Sebelas Maret \\ b Pendidikan Bahasa dan Sastra Daerah, Pascasarjana, Universitas Sebelas Maret \\ ${ }^{c}$ Pendidikan Bahasa dan Sastra Daerah, Pascasarjana, Universitas Sebelas Maret \\ 1 novitaherdiawatiI7@gmail.com*; s.slametsubiyantoro@staff.uns.ac.id; nugraheniekowardani_99@staff.uns.ac.id \\ *korespondensi penulis
}

\begin{tabular}{ll}
\hline Informasi artikel & \\
\hline Sejarah artikel: & \\
Diterima & $: 27$ Maret 2020 \\
Revisi & $:$ Oktober 2020 \\
Dipublikasikan & $:$ Oktober 2020 \\
\hline
\end{tabular}

ABSTRAK

Kata kunci:

Budaya Jawa

Bahasa Indonesia Bagi Penutur Asing

Pembelajaran

Novel

Program Bahasa Indonesia bagi Penutur Asing (BIPA) dalam proses pembelajarannya tidak terlepas dari materi kebudayaan. Sesuai dengan capaian pembelajaran aspek kebudayaan menjadi materi ajar dalam program BIPA. Aspek kebudayaan perlu diperkenalkan kepada pembelajar BIPA untuk menghindari keterkejutan budaya (culture shock) karena mereka akan bersinggungan langsung dengan masyarakat Indonesia dengan beragaman tradisi, agama, maupun suku. Tujuan penelitian ini mendeskripsikan dan menjelaskan unsur kebudayaan dalam novel Entrok karya Okky Madasari sebagai media pengenalan budaya bagi pembelajar BIPA. Objek penelitian difokuskan pada novel Entrok karya Okky Madasari. Teknik pengumpulan data melalui dua cara yaitu kajian pustaka dan baca-catat. Penelitian ini termasuk jenis kualitatif dengan analisis interaktif. Hasil penelitian yang diperoleh menunjukkan bahwa terdapat tujuh unsur kebudayaan yang terkandung dalam novel Entrok karya Okky Madasari. Unsur kebudayaan tersebut meliputi bahasa, pengetahuan, peralatan dan teknologi, mata pencaharian, sistem religi, organisasi sosial dan kesenian. Melalui ketujuh unsur tersebut, novel Entrok karya Okky Madasari dapat dijadikan sebagai media pengenalan budaya Jawa bagi pembelajar BIPA tingkat CI dan C2. Pembelajaran menggunakan aspek budaya masih mengedepankan prinsip pemahaman bahasa dalam berkomunikasi.

Key word: Javanese Culture Indonesian for Foreign Speakers Learning

Novel

\section{ABSTRACT}

The Indonesian Language Program for Foreign Speakers (BIPA) in the learning process is inseparable from cultural material. In accordance with the achievements of learning aspects of culture into teaching material in the BIPA program. Culture must be introduced to BIPA learners to avoid culture shock because they will come into direct contact with Indonesian people with a variety of traditions, religions, and tribes. The purpose of this study is to analyze the cultural elements in the novel Entrok by Okky Madasari as a medium for cultural recognition for BIPA students. The object of research is focused on the Entrok novel by Okky Madasari. Data collection techniques through two events, namely literature review and reading. This research is a qualitative type with interactive analysis techniques. The results showed that there are seven cultural elements contained in the novel Entrok by Okky Madasari. The cultural elements consist of language, knowledge, equipment and technology, social organizations, livelihoods, religious systems and arts. Through these seven elements, Entrok's novel by Okky Madasari can be used as a medium of introduction to Javanese culture for BIPA learners at CI and C2 levels. Learning using cultural aspects still emphasizes the principle of understanding language in communication. 


\section{Pendahuluan}

Kebudayaan dapat dipelihara melalui program BIPA. Pada perkembanganya, program BIPA mengalami perubahan yang signifikan dengan didukung juga oleh adanya darmasiswa. Tujuan dari darmasiswa pada dasarnya untuk menumbuhkan minat warga negara asing terhadap pengembangan bahasa dan seni budaya. Melalui program BIPA mereka tidak sekedar belajar di perguruan tinggi namun juga belajar melalui masyarakat sekitar. Data dari kemendikbud.go.id bahwa sejak tahun 1974 terdapat II7 negara dengan jumlah peserta 7.852 yang sudah mengadakan program BIPA. Pengenalan budaya Indonesia dimaksudkan untuk menghindari konflik budaya mengingat bahwa pembelajar BIPA memiliki latar belakang budaya yang beragam (Suyitno, 2017). Oleh karena itu program BIPA menjadi penting untuk terus dikembangkan.

Pentingnya pengenalan budaya bagi pembelajar Bipa untuk menghindari culture shock. Beragamanya kebudayaan yang dimiliki dari masing-masing mahasiswa asing tidak dipungkiri akan terjadinya lintas budaya, etnis maupun agama. Terbukti dari penelitian Sariningsih dkk (2017) terhadap subjek dari Belanda yang mengalami beberapa culture shock salah satunya berkaitan dengan ritual keagamaan masyarakat Bali baik dari persembahan yang ada di setiap jalan dan upacara atau ritual yang menutup akses jalan. Oleh karena itu, pemahaman budaya bagi pembelajar Bipa perlu dilakukan untuk tujuan memudahkan komunikasi karena mereka akan tinggal dan berinteraksi dengan masyarakat.

Salah satu karya sastra yang memuat unsur mengenai budaya adalah novel Entrok. Dokumentasi kebudayaan pada tahun 70-an menjadi daya tarik yang ditawarkan pada novel ini. Latar sosial novel Entrok berada di daerah Madiun, Jawa Timur dengan desa kecil bernama Singget. Aktivitas pedesaan yang masih murni dengan segala kebiasaan bermasyarakat, ritual agama, sampai tentang cara pandang mengenai sesuatu hal. Keseluruhanya digambarkan dengan bahasa ringan dan sarat makna.

Kebudayaan yang tergambar dalam novel Entrok dominan membahas mengenai zaman pasca penjajahan. Kebudayaan pada tahun 70-an yang dicerminkan dalam novel kenyataannya beberapa masih bertahan hingga sekarang. Hal ini menandakan bahwa kebudayaan itu sudah mengalir dalam diri masyarakat dimana mereka tinggal dan sudah menjadi kekhasan. Melalui kekhasaan budaya yang dimiliki daerah tertentu dapat membantu pembelajar BIPA untuk berbahasa secara wajar seperti halnya orang Indonesia karena pada dasarnya budaya berkaitan erat dengan bahasa. Dengan demikian, unsur budaya dalam novel Entrok menjadi sesuatu yang penting untuk menunjang keberhasilan pengajaran BIPA.

Karya sastra terutama novel memuat dokumentasi budaya yang didasarkan atas realitas yang ada dalam masyarakat. Pengarang menciptakan sebuah karya sastra tidak terlepas atas interaksinya dengan lingkunganya. Pradopo (200I: 6I) juga menekankan bahwa karya sastra lahir atas dasar imajinasi dan refleksi pengarang terhadap gejala sosial disekitarnya. Gejala sosial dalam hal ini termasuk kebiasaan maupun tradisi masyarakat yang kemudian dituangkan melalui teks sastra.

Kebudayaan pada hakikatnya adalah keseluruhan gagasan, tingkah laku dan hasil karya manusia termasuk kepercayaan, pengetahuan, moral, adat istiadat, hukum ataupun kebiasaan lain yang diperoleh melalui belajar dalam suatu lingkungan masyarakat (Koentjaraningrat, 2009: I44; Endraswara, 2013: I0). Secara umum kebudayaan berakar dari pemikiran manusia yang dibuktikan melalui tindakan-tindakan serta benda-benda.

Kebudayaan dalam penelitian ini didasarkan atas unsur kebudayaan universal yang dikemukan oleh Koentjaraningrat. Tujuh unsur kebudayaan tersebut meliputi bahasa, religi, pengetahuan, organisasi sosial, teknologi dan peralatan hidup, kesenian dan sistem mata pencaharian (2009: 264269). Keseluruhan unsur tersebut ditelaah dan dianalisis untuk dijadikan sebagai alternatif materi ajar bagi pembelajar bipa.

Penelitian sebelumnya juga sudah membahas mengenai pembelajar BIPA yang dikaitkan dengan budaya Indonesia yaitu Pemanfaatan Keberagaman Budaya Indonesia Dalam Pengajaran Bahasa Indonesia Bagi Penutur Asing (Bipa) oleh Ruskhan (2010), Memperkenalkan Budaya Daerah: Janias, Tokoh Nyata dalam Film Denias, Senandung di Atas Awan sebagai Salah Satu Alternatif Pengajaran Sastra bagi Pembelajar BIPA oleh Hasanudin (2016), Menguak Kearifan Lokal Budaya Suran di Surakarta Sebagai Bahan Ajar Bahasa Indonesia Untuk Penutur Asing oleh Kurniawan dan Gunawan (2016). Perbedaan penelitian terletak pada fokus kajianya yaitu unsur budaya yang terdapat dalam adalah novel Entrok karya Okky Madasari.

Berdasarkan beberapa alasan di atas, secara khusus penelitian ini bertujuan untuk membahas mengenai unsur budaya yang terdapat dalam novel Entrok sebagai alternatif pengenalan budaya Indonesia bagi pembelajar BIPA. Harapanya materi pengajaran aspek kebudayaan dalam pembelajaran BIPA tidak hanya berfokus pada apa yang tertuang 
di modul namun dapat melalui novel. Hal itu akan memberikan pembelajar BIPA wawasan kebudayaan Indonesia yang luas.

\section{Metode}

Penelitian ini menggunakan pendekatan kualitatif. Pendekatan kualitatif digunakan untuk mendeskripsikan dan menjelaskan fenomena budaya yang dikaitkan dengan pembelajaran Bipa. Objek penelitian ini difokuskan pada unsur kebudayaan. Sumber data penelitian berasal dari novel Entrok karya Okky Madasari. Teknik pengumpulan dalam memperoleh data menggunakan kajian Pustaka dan baca-catat. Kajian pustaka digunakan sebagai pengumpulan data dengan menganalisis serta menelaah buku. Baca catat dimaksudkan untuk mencatat hasil bacaan dari novel Entrok karya Okky Madasari yang berhubungan dengan fokus penelitian.

Analisis data penelitian ini mengacu pada model alir yang dipaparkan oleh Miles dan Huberman meliputi pengelompokkan data, menyajikan data, dan penrikan kesimpulan (20I2: I5-19). Analisis data dimulai dengan mereduksi data dengan cara mengelompokkan data yang sesuai dengan permasalahan yaitu unsur budaya. Selanjutnya data disajikan berdasarkan pengelompokkan serta dianalisis secara mendalam sehingga ditemukan sebuah kesimpulan.

\section{Hasil dan Pembahasan}

\section{Unsur Budaya dalam Novel Entrok Bahasa}

Penggunaan bahasa yang ditemukan dalam novel Entrok karya Okky Madasari adalah bahasa Jawa. Penggunaan bahasa Jawa dipengaruhi oleh latar novel tersebut berada di desa Singget, Magetan, Jawa Timur. Penggunaan bahasa Jawa ditunjukkan melalui kutipan berikut ini.

"Aku tidak punya Bapak, Bulik. Aku tidak tahu dimana dia," jawabku bergetar. Mataku mulai berkaca-kaca.

"ya, makanya itu. Kalau sudah tahu bapak saja nggak punya, ya sudah. Nggak usah neko-neko. Bisa makan tiap hari saja sudah syukur." (hlm, I9)

Kata "Bulik" pada kutipan data di atas menunjukkan bahwa terdapat penggunaan bahasa Jawa. Bulik digunakan masyarakat Jawa untuk panggilaan sapaan kepada adik perempuan dari ayah atau ibu. Jika dalam bahasa Indonesia Bulik sama artinya dengan Tante. Namun sampai sekarang panggilan Bulik masih digunakan pada masyarakat Jawa.

"Nuwun sewu, Pak Lurah, saya pengin bisa membantu. Tapi lima puluh itu rasanya terlalu besar. Saya kok rasanya tidak mampu kalau sebesar itu," kata Ibu. (hlm, 79)

Nuwun sewu artinya permisi. Masyarakat Jawa terkenal dengan sikap sopan santun kepada seseorang yang dianggap status sosialnya lebih tinggi. selain itu, nuwun sewu termasuk dalam tingkatan bahasa krama yang dikhususkan untuk berbicara kepada orang yang lebih tua atau stratanya lebih tinggi.

"Nggak bisa, Pak Guru. Ngapunten. Mungkin orang lain bisa membantu." (hlm, 88)

Kata ngapunten berarti maaf. Beberapa orang Jawa memiliki kebiasaan untuk memperhalus penolakan mengawali dengan mohon maaf. Tujuanya agar tidak menyinggung lawan bicara. Sumarni bermaksud menolak permintaan Pak Guru Waji yang ingin meminjam uang sehingga agar tidak menyinggungnya ia mengatakan ngapunten.

Berdasarkan pemaparan di atas, bahasa yang digunakan pada beberapa kutipan tersebut merupakan bahasa masyarakat Jawa sebagai alat komunikasi sehari-hari yang dituangkan dalam cerita.

\section{Sistem Pengetahuan}

Pengetahuan dalam hal ini didasarkan pada cara manusia mengolah dan membuat apa yang ada disekitarnya yang dapat digunakan untuk bertahan hidup. Pengetahuan dalam novel Entrok dimanifestasi dari tokoh-tokoh dalam cerita. Data pertama mengenai pengetahuan tokoh Nyi Dimah dalam memanfaatkan dan mengolah singkong menjadi makanan pokok.

Tidak semua penjual singkong di pasar ini sepintar Nyai Dimah, bisa mengolah singkong menjadi gaplek sebelum di jual. (hlm, 24)

Nyi Dimah adalah pedagang gaplek singkong yang terkenal di pasar Ngranget. Masyarakat Jawa pada zaman dahulu memanfaatkan singkong sebagai makanan pokok pengganti nasi. Bagi masyarakat ekonomi menengah ke bawah, nasi merupakan makanan yang mewah sehingga mereka memilih gaplek yang harganya lebih terjangkau. Gaplek adalah singkong yang dikeringkan.

Aku mulai rajin mencari kunir yang tertanam di sembarang tempat di Singget. Kunir itu kuparut lalu diperas dengan air. Kata simbok, kalau aku minum kunir tiap hari, perutku tak akan sakit lagi saat keluar darah nanti. (hlm, 33)

Pengetahuan yang dimiliki masyarakat Jawa selanjutnya adalah mengenai pengobatan. Sumarni yang mulai beranjak dewasa mengalami nyeri perut 
akibat menstruasi. Masyarakat Jawa mempercayai bahwa jamu kunir dapat meredakan rasa nyeri akibat menstruasi. Pengetahuan mengenai pengobatan tradisional yang disebut jamu masih berkembang sampai sekarang.

Sudah tiga hari au tidak ke pasar. Badanku meriang. Dari pagi hingga malam aku mencret. Rahayu membuatkanku bubur untukku. Dia juga mengerik punggungku dengan irisan bawang dan minyak goreng. (hlm, 276)

Selain pengobatan melalui jamu, terdapat pengetahuan mengenai kerokan. Sumarni merasa tidak enak badan dan meminta rahayu untuk mengerik punggungnya. Masyarakat Jawa di Indonesia memiliki pengobatan tradisional berupa kerokan. Kerokan dilakukan dengan cara mengerik punggung dengan koin dan minyak sampai menimbulkan warna merah. Biasanya kerokan digunakan untuk menyembuhkan penyakit masuk angin.

Esok harinya, sapi yang kubeli disembelih. Dagingnya dicacah-cacah untuk rawon. (hlm, 279)

Kutipan di atas mencerminkan pengetahuan masyarakat Jawa dalam mengolah daging menjadi rawon. Makanan khas Jawa Timur ini dimasak seperti sup dengan warna kuah yang hitam. Warna hitam berasal dari rempah kluwak. Sumarni menyajikan rawon pada saat mengadakan selametan kematian Teja suaminya.

Beberapa kutipan di atas mengindikasikan sistem pengetahuan yang ada dalam novel Entrok yang beragam. pengetahuan tersebut berupa olahan singkong menjadi gaplek, pengobatan tradional jamu dan kerokan, serta pengolahan daging menjadi masakan rawon. Keseluruhan pengetahuan tersebut berkembang dan menjadi kebiasaan masyarakat.

\section{Organisasi sosial}

Organisasi sosial berhubungan dengan perkumpulan atau komunitas sosial yang dibentuk masyarakat untuk kepentingan tertentu. Beberapa organisasi sosial ini tidak berbadan hukum dan ada pula yang berbadan hukum

Pak Lurah yang dulu hanya datang ke rumah saat mau pemilu, sekarang bisa datang kapan saja. Minta sumbangan buat pembangunan gardu di dukuh sana atau di dukuh sini. Kalau gardunya sudah dibangun, ganti pemuda-pemuda desa yang datang. Mereka meminta duit keamanan. Pemudapemuda ini akan ronda sepanjang malam, menjaga orang-orang Singget yang sudah terlelap. (hlm, I28)

Organisasi kepemudaan masih menjadi bagian yang sampai sekarang ada dalam masyarakat. Kutipan di atas menunjukkan adanya organisasi pemuda di desa yang berfungsi membantu tugas tantara menjaga keamaan desa dengan ronda. Organisasi tersebut pada dasarnya tidak berasaskan hukum.

\section{Sistem Teknologi dan Peralatan Hidup}

Teknologi dan peralatan hidup berhubungan dengan segala sesuatu yang digunakan manusia dalam kehidupannya. Novel Entrok karya Okky Madasari memuat beberapa peralatan dan teknologi yang digunakan tokoh dalam cerita. Salah satunya tenggok yang terdapat dalam kutipan berikut.

Aku dan Simbok keluar bukan satu-satunya orang yang menyusuri jalanan pagi ini. Di depan kami, di belakang, juga di samping, perempuanperempuan menggendong tenggok menuju Pasar Ngranget. (hlm, 22)

Peralatan yang terdapat dalam fragmen di atas adalah tenggok. Tenggok digunakan masyarakat Jawa tempo dulu untuk membawa barang-barang baik barang dagangan maupun hasil panen. Cara membawanya dengan digendong di punggung dengan kain. Peralatan tersebut terbuat dari anyaman bambu dengan bentuk bulat melebar. Masyarakat desa Singget menggunakan tenggok untuk membawa barang dagangan ke pasar Ngranget.

Nyai Wedana menyuruhku memanggil andong yang mangkal di seberang jalan. (hlm, 38)

Teknologi selanjutnya berkaitan dengan kendaraan tradisional. Nyai Wedana dalam kutipan di atas meminta Rahayu untuk memanggil andhong sebagai kendaraan untuk mengantarkanya pulang. Andhong menjadi transportasi umum dengan memanfaatkan tenaga kuda. Pada saat ini keberadaan andhong sudah berkurang karena banyaknya kendaraan bermesin.

\section{Sistem Mata Pencaharian}

Sistem mata pencaharian sama halnya dengan pekerjaan yang menjadi sumber untuk manusia bertahan hidup. Mata pencaharian yang terdapat dalam novel Entrok karya Okky Madasari meliputi pedagang, kuli, petani tebu, dan pegawai pabrik gula yang dapat dilihat pada kutipan berikut ini.

"Jualan singkong bertahun-tahun menjadi pekerjaan Nyi Dimah, perempuan yang memperkerjakan kami." (hal. 24)

"Mbah Noto kuli paling tua yang bekerja paling awal dibanding kuli lain, hanya ingat dia sudah nguli pada zaman Jepang” (hal. 36)

Kedua kutipan di atas menunjukkan sistem mata pencaharian masyarakat desa Singget. Beberapa masyarakat desa Singget beraktivitas di 
Pasar Ngranget, sehingga pekerjaan mereka tidak jauh dari seorang pedagang dan kuli pasar.

"Hari ini tebu di sawahku akan mulai ditebang. Pabrik Purwadadi sudah menyiapkan lorinya untuk mengangkut seluruh tebu yang dipanen di kecamatan ini, termasuk tebu milikku." (hal. I02)

"Marijo adalah pegawai bagian pembayaran di pabrik gula. Saat ada tebang tebu, dia ke sawahsawah, mengawasi tebu-tebu yang diangkut ke lori, menghitung, lalu menyerahkan uang pembelian kepada pemilik sawah.”(hal. 200)

Dua kutipan di atas menunjukkan sistem mata pencaharian masyarakat Singget sebagai petani tebu dan pegawai pabrik gula. Beberapa memilih menjadi petani tebu karena harganya setiap tahun meningkat. Selain itu, pegawai pabrik gula pada saat itu dianggap menjanjikan karena gajinya besar.

Berdasarkan pemamparan di atas, sistem mata pencaharian yang paling dominan dalam novel Entrok karya Okky Madasari adalah pedagang dan petani tebu. Pedagang menjadi profesi yang paling diminati karena mereka tidak lepas dari kehidupan pasar. Beberapa masyarakat di desa Singget juga percaya bahwa tebu adalah tanaman yang tidak mengenal musim sehingga mereka menggantungkan diri pada tebu.

\section{Religi}

Sistem religi adalah keseimbangan antara kepercayaan dengan aktivitas keagamaan yang dianut dalam masyarakat. Sistem religi yang terdapat dalam novel Entrok digambarkan melalui kebiasaan berdoa di malam hari di bawah pohon, slametan dan berziarah ke makam leluhur. Berikut dapat di lihat pada kutipan berikut ini.

"Nduk terserah apa penginmu. Yang penting, coba nyuwun sama Mbah Ibu Bumi Bapa Kuasa. Semua kejadian hanya terjadi kalau Dia yang menginginkan." (hal. 42-43)

Kutipan di atas menunjukkan kebiasaan tokoh utama Sumarni berdoa kepada leluhur di malam hari. Sumarni percaya bahwa segala sesuatu yang diharapkan akan dikabulkan oleh Mbah Ibu Bumi Bapa Kuasa. Selain itu, Sumarni juga sering melakukan slametan dengan berbagai sesajen yang dapat dilihat pada kutipan berikut ini.

"Ibu juga rajin selametan. Seminggu sekali, setiap hari kelahiranya, dia menyembelih ayam untuk dipanggang. Tonah membuat tumpeng kecil , menyiapkan semua ubo rampe. Ada kulupan, jenang merah, dan jenang putih. Ibu memanggil beberapa tetangga laki-laki. Mbah Sambong, perangkat desa yang punya kekuatan lebih, membacakan ujub. Bapak dan yang lainya membacakan , "Amin... Amin...!" (hal. 56)

Selametan dilakukan oleh Sumarni dengan tujuan untuk mendapatkan keselamatan dan kedamaian hidup. Dalam teori kebudayaan Jawa sistem religi yang demikian disebut dengan islam abangan. Koentjaraningrat (I984: 3I2) menjelaskan bahwa islam abangan atau kejawen pada dasarnya keyakinan yang masih terpengaruh oleh HinduBudha, biasanya cenderung mistik.

\section{Kesenian}

Kesenian dalam unsur kebudayaan sebagai hasil cipta manusia yang mengandung rasa keindahan atau bernilai estetika. Kesenian yang digambarkan dalam adalah novel Entrok karya Okky Madasari berupa kesenian musik gambyong.

"Kami tiba di rumah saat malam telah larut. Tak ada lagi orang lalu lalang. Suara gamelan dan teriakan "Cayo!" para penari gambyong terengar sayup-sayup. Mereka akan terus berpesta sampai terdengar kokok ayam.” (hal. 66)

Gambyong pada kutipan di atas merupakan kesenian klasik khas Jawa Timur yang berupa tarian dengan iringan musik gamelan. Gambyong pada konteks kutipan di atas dimainkan untuk merayakan pesta pasca pemilu.

“...mereka berpakaian jawa, beskap dengan kepala ditutupi blangkon. Tandu itu dihiasi dengan janur dan melati, persis seperti tandu pengantin. Tapi yang ada di dalam tandu bukab manusia, melainkan dua tebu yang juga dihiasi dengan kantil dan melati. Itulah Temanten Tebu. ” (hal. I04)

Kutipan di atas menunjukkan bahwa masyarakan desa Singget memiliki pakaian tradisional Jawa yaitu beskap dan blangkon. Beskap pakaian adat tradisional yang digunakan oleh lakilaki pada saat acara tertentu. Selain itu, beskap dilengkapi dengan penutup kepala yang bernama blangkon.

\section{Novel Entrok Sebagai Media Pengenalan Budaya Bagi Pembelajar BIPA}

Pengenalan budaya bagi pembelajar BIPA harus dilakukan secara bertahap sesuai dengan prinsip pembelajaran. Hal ini didasarkan karena masing-masing peserta BIPA berasal dari berbagai negara yang memiliki ragam budaya. Prinsip pembelajaran BIPA perlu memperhatikan sasaran dari BIPA, yaitu penutur yang belum mengenal bahasa Indonesia, latar budaya dan bahasa yang 
bervariasi, usia, tujuan yang berbeda, dan kompetensi tertentu (Kusmiatun (2016: 40). Oleh karena itu, pengenalan budaya penting untuk dilakukan pada peserta BIPA. Suminto A. Sayuti berpendapat bahwa dibandingkan cerita semu dalam buku ajar BIPA, potongan cerpen atau novel secara tidak langsung lebih menghanyutkan pelajar asing (Assidiq, diakses I6 Juli 20I dari http://republika.co.id).

Novel Entrok dapat dijadikan sebagai media pembelajaran bagi pembelajar BIPA, karena mengandung beberapa unsur budaya Indonesia salah satunya budaya Jawa. Seperti yang telah dipaparkan di pendahuluan bahwa budaya perlu dikenalkan kepada mahasiswa asing untuk menghindari kesalahpahaman dalam berkomunikasi. Misalnya kebiasaan masyarakat Jawa melakukan selametan dengan berbagai sajian dan persembahan dapat saja mengganggu atau dianggap aneh bagi mereka. Oleh karena itu, perlu materi ajar yang dapat membuat mahasiswa asing terutama yang belajar BIPA mengerti dan memahami tujuan dari kebiasaan tersebut. Selanjutnya, kebiasaan orang Indonesia yang santun dengan mengucapkan permisi atau maaf yang dalam konteks cerita dimunculkan melalui bahasa Jawa. Hal tersebut dapat digunakan sebagai materi ajar dalam pembelajaran ranah aspek budaya masyarakat Indonesia. Materi ajar yang bervariatif yang tidak melulu menggunakan modul akan menambah motivasi pembelajar BIPA dalam belajar bahasa Indonesia.

Program BIPA yang dikemas dengan kebudayaan akan membuat penutur asing lebih tertarik untuk mempelajarinya. Budaya dalam hal ini bukanlah prioritas pembelajaran namun sebagai sarana dalam penguasaan bahasa. Muatan budaya dapat dimanfaatkan untuk bahan pembelajaran pada semua tingkatan baik pembelajar BIPA yang mempunyai keterampilan berbahasa tingkat dasar maupun tingkat mahir (Yolferi, 2019). Oleh karena itu, agar pembelajaran relevan, budaya yang diajarkan juga perlu menyesuaikan dengan kebutuhan, tingkat pemahaman dan penguasaan bahasa dari penutur (Junaidi dkk, 2017). Pembelajar BIPA dalam hal ini pada tingkat CI dan C2. Tingkat ini menggolongkan pembelajar BIPA yang sudah mahir berbahasa Indonesia. Materi apresiasi sastra mengacu pada standar kompetensi C-2.7 Mampu mengidentifikasi unsur kebahasaan dan fungsi sosial dalam karya sastra untuk menangkap pesan yang disampaikan. Dengan demikian, aspek budaya yang dikenalkan pada pembelajar BIPA sesuai dengan capaian pembelajaran dan dapat mendukung penguasaan berbahasa Indonesia.

\section{Simpulan}

Novel Entrok karya Okky Madasari secara umum dapat dijadikan sebagai media pengenalan budaya Jawa bagi pembelajar BIPA karena mengandung unsur kebudayaan yang meliputi bahasa, sistem pengetahuan, sistem mata pencaharian, sistem religi dan keseian. Keseluruhan unsur tersebut dapat memberikan gambaran mengenai budaya Jawa pada pembelajar BIPA tingkat CI dan C2. Tingkat CI dan C2 dalam pembelajaran BIPA termasuk kategori mahir, dimana mereka sudah dapat berbahasa Indonesia dengan baik. Standar kompetensi yang dikeluarkan oleh PPSDK, pembelajar BIPA dituntut untuk dapat mengapresiasi sastra. Pembelajaran apresiasi sastra yang dilakukan oleh pembelajar BIPA tentunya juga sampai pada tahap mengenal kebudayaan dengan tujuan sebagai bekal berkomunikasi.

\section{Daftar Pustaka}

Junaidi, dkk. (2017). Implementasi Pembelajaran BIPA Berbasis Budaya Sebagai Strategi Menghadapi Mea. Education and Language International Conference Procedings Center of Unissula.

Kusmiatun, A. (2016). Mengenal BIPA (Bahasa Indonesia Penutur Asing) dan Pembelajarannya. Yogyakarta: K-Media.

Koentjaraningrat. (1989). Kebudayaan Jawa. Jakarta: Balai Pustaka.

Koentjaraningrat. (2009). Pengantar Ilmu Antropologi. Jakarta: PT Rineka Cipta.

Ruskhan, A. G. (20I0). Pemanfaatan Keberagaman Budaya Indonesia Dalam Pengajaran Bahasa Indonesia Bagi Penutur Asing (Bipa). Jurnal Sawerigading, I6 (I).

Kurniawan, E dan Boby Gunawan. (2016). "Menguak Kearifan Lokal Budaya Suran di Surakarta Sebagai Bahan Ajar Bahasa Indonesia Untuk Penutur Asing”. Proseding Konferensi $B I P A$.

Hasanudin, D. (2016). Memperkenalkan Budaya Daerah: Janias, Tokoh Nyata dalam Film Denias, Senandung di Atas Awan sebagai Salah Satu Alternatif Pengajaran Sastra bagi Pembelajar BIPA. Proseding Language Education and Literature.

Miles, M.B dan Huberman, A.M. (2012). Analisis Data Kualitatif. Jakarta: UI Press. 
Pradopo, R. D. (200I). Metodologi Penelitian Sastra. Yogyakarta: PT Hanindita Graha Widya.

Sariningsih, N.I., dkk. (2017). An Analysis of Culture Shock of Bipa Student In UPT Bahasa. JPBI, Vol. 5(2).

Suyitno, Imam. (2017). Aspek Budaya Dalam Pembelajaran Bahasa Indonesia Bagi Penutur Asing (Bipa). Proseding Seminar Nasional Bahasa dan Sastra dalam Konteks Global.

Yolferi. (2019). Kearifan Lokal Dalam Cerita Rakyat Sebagai Media Pengenalan Budaya Dalam Pembelajaran Bahasa Indonesia Bagi Penutur Asing. Prosding Kongres Bahasa Indonesia 